\title{
MANUAIS DIDÁTICOS DE HISTÓRIA DO BRASIL NO COLÉGIO PEDRO II: DO IMPÉRIO ÀS PRIMEIRAS DÉCADAS DA REPÚBLICA*
}

\author{
Gilberto Luiz Alves \\ gilbertoalves9@uol.com.br \\ Universidade Anhanguera-Uniderp
}

\begin{abstract}
RESUMO:
O presente trabalho visa contribuir para a apreensão da história dos manuais didáticos no Brasil. Reportando-se ao período compreendido entre o Império e as décadas iniciais da Primeira República, usa como referência os manuais didáticos de História do Brasil adotados no Colégio Pedro II. A temática selecionada para a realização da análise de conteúdo é a Guerra da Tríplice Aliança. De acordo com os limites teóricos e documentais desta abordagem inicial, podem ser resumidas algumas conclusões. Quanto à sua função no trabalho didático, tais instrumentos subordinaram-se a uma concepção que implicava uma limitada incorporação da divisão do trabalho, cerceando a realização de um maior grau de simplificação e objetivação da atividade de ensino. Os professores eram vistos como profissionais que exerciam o controle do trabalho e a organização do trabalho didático encontrava-se num estágio muito aquém da concepção comeniana. Quando os manuais didáticos recontaram o evento referido se limitaram a incorporar a interpretação consagrada pela área de história militar; reduziram a descrição do conflito ao plano político, radicando suas causas nas desavenças diplomáticas dos vizinhos platinos e, quanto ao conflito propriamente dito, cingiram-se à descrição positivista dos embates armados.
\end{abstract}

Palavras-chave: História da Educação; Trabalho Didático; Manuais Didáticos; História do Brasil

\section{DIDACTICAL MANUALS OF BRAZIL HISTORY AT COLLEGE PEDRO II: FROM THE EMPIRE TO THE FIRST DECADES OF THE REPUBLIC}

\begin{abstract}
:
The present work aims to contribute to the history apprehension of the didactical manuals in Brazil. Referring to the period understood between the Empire and the initial decades of the First Republic, it uses like reference the didactical manuals of the History of Brazil adopted at College Pedro II. The theme selected for the realization of the content analysis is the Triple Alliance War. According to the theoretical and documental limits of this initial approach, some conclusions can be summarized. As for their function in the didactical work, such instruments followed a conception that was a limited incorporation of the division of the work, stifling the realization of a bigger degree of simplification and objectivity of the teaching activity. The teachers were seen as professionals who practiced the control of the work and the organization of the didactical work was in a much smaller stage of comenian's conception. When the didactical manuals retold the mentioned event they limited to incorporating the interpretation consecrated by the military history area; reduced the conflict description to the political plan, consolidating their causes on the diplomatic conflicts of the Platine neighbors and, as for the conflict, joined to the positivist description of the armed struggles.
\end{abstract}

Keywords: History of Education; Educational Work; Didactical Manuals; History of Brazil. 
Os estudiosos de história da educação têm reiterado o estágio inicial em que se encontram as pesquisas referentes aos manuais didáticos no Brasil. Como decorrência, constata-se, também, que a maior parte das investigações focadas sobre tal objeto não afirma o propósito de reconstituir a história desses instrumentos de trabalho como um todo. Restringe-se, prudentemente, a períodos claramente delimitados, que envolvem poucas décadas (Lins, 1977; Freitag, Costa e Motta, 1997; Gatti Júnior, 2004). Bittencourt é quase uma exceção. Ao se propor a abordar "a história do livro didático no processo de constituição do ensino escolar brasileiro no decorrer do século XIX e primeiros anos do século XX" (Bittencourt, 2008, p. 13) reporta-se a um extenso período ${ }^{1}$.

Os estudos pontuais, que incidem sobre lapsos de tempo mais restritos, não são eles próprios recursos para configurar a gênese e todas as fases de desenvolvimento do manual didático entre nós. Mas sem eles é impossível fazer a reconstituição histórica dos processos de produção, de utilização e detecção das características desse instrumento de trabalho do professor. Quando reunidos, eles permitem reconstruir passos do processo, contribuindo assim para a elaboração de uma síntese inicial, ainda que precária e incompleta.

Mesmo em face das relevantes contribuições já produzidas pela pesquisa científica, tanto as propiciados por investigações pontuais quanto as intentadas por estudos sintéticos de maior fôlego, focados sobre períodos mais extensos, a história dos manuais didáticos no Brasil ainda está, em grande parte, por ser feita. Para balizar o nosso entendimento de como a pesquisa pode contribuir para a elaboração dessa história, as iniciativas de análise dos manuais didáticos precisam tomar como referência dois aspectos essenciais: o seu conteúdo e a sua historicidade, esta revelada pelas suas funções no âmbito do trabalho didático. Como as dificuldades que cercam a compreensão desses aspectos em muitas análises são, sobretudo, de caráter teórico, a discussão subseqüente retoma o que de essencial já está assentado sobre a matéria.

Necessariamente, o foco inicial deve incidir sobre a especificidade do manual didático no âmbito da escola moderna. Enquanto instrumento do trabalho didático, o manual existe desde muito tempo. Contudo, a escola moderna, tal como a pensou Comenius, lhe conferiu funções precisas que interferiram profundamente na relação educativa, dando origem, inclusive, a uma nova forma histórica de organização do trabalho didático ${ }^{2}$. Por isso, qualquer discussão sobre o manual didático moderno não pode nivelá-lo ou reduzi-lo aos seus antecessores, sob pena de se perder a sua especificidade e, portanto, a sua historicidade. Ao mesmo tempo, não se deve supor que a emergência do manual didático moderno realizou uma ruptura radical, de imediato, com as suas formas preexistentes.

Para o estudioso da educação brasileira essas duas considerações iniciais são básicas, pois alertam para duas fontes de erros que, se não tangenciadas, inutilizam os resultados de quaisquer investigações históricas sobre a matéria. Do ponto de vista prático, isto faz o pesquisador se defrontar com o fato de o Brasil nunca ter correspondido às formas mais desenvolvidas do capitalismo e, como uma de suas decorrências, ter construído o seu sistema nacional de ensino a partir das idéias e experiências daquelas nações que estavam no epicentro do desenvolvimento da sociedade burguesa. Logo, o exame do processo de produção da escola moderna, no Brasil, exige chave teórica mais universal que o torne inteligível e revele a sua própria singularidade. Como a organização manufatureira do trabalho didático tem sido dominante desde o século XVII, a produção teórica de seu principal mentor, Comenius, credencia-se como essa chave teórica mais universal. Portanto, se reconhece que o pensamento desse notável educador protestante é angular para a compreensão do desenvolvimento da escola moderna no Brasil (Alves, 2005, p. 59-76). É um equívoco descartar a sua proposta, que se encontra detalhadamente 
descrita em Didática Magna (Coménio, 1976, 525 p.), pelo fato de ter germinado no interior da Reforma e, como decorrência, por se associar a práticas religiosas e educacionais diferentes daquelas experimentadas pelo Brasil e por Portugal, nações historicamente vinculadas à Contra-Reforma. Do ponto de vista metodológico trata-se, tão simplesmente, de explicar uma forma histórica menos desenvolvida por meio da mais desenvolvida, o que não representa a negação da especificidade da educação escolar brasileira como alguns imaginam. Pelo contrário, a construção da explicação exige o esforço teórico, nem sempre fácil de ser realizado, de demonstrar como, por mediações, são válidos os pressupostos gerais da proposta comeniana, mas de forma a captar e revelar a singularidade brasileira. O presente trabalho é um exercício teórico-metodológico que, entre outras intenções, procura demonstrar a correção dessa postura.

A hipótese é a de que, por não ser uma nação capitalista desenvolvida, o Brasil começou tardiamente a construir os manuais didáticos modernos e que a sua forma de realização ainda não ganhara, no século XIX e início do século XX, as características e as funções que esses instrumentos do trabalho didático incorporaram na proposta comeniana.

Como o período analisado é o referente ao Império e às primeiras décadas da República, atente-se, de início, para o lapso em torno de dois séculos que separava essa época do momento em que foi publicada a obra Didáctica Magna. Para aclarar os contornos gerais da proposta veiculada nessa obra clássica, a exposição subseqüente recoloca, sob a forma de uma resumida paráfrase, o que de essencial foi dito sobre a matéria no livro A produção da escola pública contemporânea (Alves, 2006, p. 71-93).

Hoje reconhecido como o principal mentor da escola moderna, à sua época Comenius combatia a relação educativa feudal que se dava entre o preceptor, de um lado, e o discípulo, de outro. Afinado com os princípios da Reforma, reivindicava a "escola para todos”, daí ter reconhecido a impossibilidade daquela relação educativa manter-se, pois encarecia sobremaneira os serviços educacionais. O barateamento desses serviços era uma condição material indispensável para viabilizar a expansão do atendimento escolar, principalmente entre os destituídos de maiores posses. Comenius reconheceu, inclusive, que o próprio preceptor, um sábio cujos serviços exigiam régios estipêndios, era um obstáculo à educação que a humanidade começava a demandar. Para propor uma nova relação educativa, já não mais a de um preceptor que tinha sob a sua responsabilidade um discípulo ou um pequeno grupo de discípulos, mas a de um educador que deveria se dirigir a um coletivo numeroso de estudantes, Comenius enfrentou, também, a necessidade de pensar uma nova instituição social. E concebeu-a tendo como parâmetro as manufaturas, que, à época, estavam em expansão e revolucionavam o artesanato medieval. Das manufaturas apropriou-se, sobretudo, da divisão do trabalho, recurso responsável pela elevação da produtividade do trabalho, por força da especialização dos trabalhadores em uma ou poucas operações do processo de trabalho. Essa especialização os levava a um ritmo febril na realização das operações correspondentes, determinado pelo condicionamento de movimentos do corpo executados repetitivamente. A base técnica continuava sendo a do artesanato, mas o dado distintivo da manufatura e que representava um salto de qualidade, frise-se mais uma vez, era a divisão do trabalho.

Para evidenciar como este homem afinado com os avanços de seu tempo pensou o trabalho didático sob a perspectiva da manufatura, é de se realçar a divisão em etapas que lhe impôs, configurada por meio das séries e dos níveis de ensino na escola moderna. Estabeleceu com clareza, igualmente, as áreas de conhecimento integrantes do plano de estudos. Essas novidades, associadas à materialidade física da instituição social que concebeu, produziram um profissional original, distinto do preceptor: com o bispo morávio nasceu o professor. 
Como o próprio artesão em relação ao seu ofício, o preceptor dominava todo o processo de formação de um jovem. Contratado, quase sempre, para acompanhar o processo de educação de seu discípulo desde tenra idade, dava por concluído o seu mister quando o jovem demonstrava ter assimilado o que de mais avançado estava compreendido nas humanidades clássicas. Já o professor comeniano tornou-se um profissional parcial, que passou a trabalhar com um determinado nível de escolarização e/ou com uma área de conhecimento. Portanto, o professor realizou-se, também, como um trabalhador especializado. Mas Comenius foi mais longe. Reconheceu a quantidade exígua de pessoas que, naquela conjuntura histórica por ele vivida, poderia dedicar-se ao magistério. Afinal, não havia tantos homens de formação reconhecida, em sua época, mesmo entre os que sabiam ler e escrever, para atender como professores à demanda de educação para todos. Por isso, desenvolveu, inclusive, a tecnologia fundamental que deveria mediar a relação entre o professor e o aluno: $o$ manual didático.

No manual didático o bispo morávio depositou a sua convicção de assegurar a transmissão do conhecimento no nível desejável, à margem de dificuldades derivadas do desconhecimento do professor ${ }^{3 \cdot}$ Dispensou outras fontes de informação e impôs o império de tal instrumento de trabalho dentro da escola, incorporando-lhe uma função excludente desde o momento de sua concepção ${ }^{4}$. Por fim, para sediar a relação educativa de professores, de um lado, e um coletivo de alunos organizado como classe, de outro, ele pensou o espaço escolar tal como o conhecemos: basicamente, um prédio com diversas salas de aula, dependências administrativas e um pátio pouco amplo. Era o que bastava à realização da formação intelectual das crianças e dos jovens.

Constata-se que, ao conceber a escola moderna, Comenius conferiu-lhe uma forma histórica concreta de organização do trabalho didático, considerada necessária em face das imensas demandas de seu tempo. Os seus três elementos constitutivos podem ser descritos da seguinte forma: 1) a relação educativa então concebida colocou de um lado o professor e, de outro, um coletivo de alunos organizado como classe; b) os procedimentos didáticos do professor e os conteúdos programados para a transmissão do conhecimento passaram a ter como fundamento uma precisa tecnologia educacional, o manual didático, c) e a sala de aula ascendeu à condição de espaço privilegiado dessa relação, pois a formação intelectual das crianças e dos jovens, à época, esgotava a função da educação escolar.

Nessa organização do trabalho didático, que se reportava à base técnica da manufatura, a ênfase foi colocada no manual didático, o instrumento por excelência do professor. Acompanhando a tendência vigente no âmbito das manufaturas, o trabalhador da educação começava a se subordinar ao instrumento de trabalho.

Prosseguindo, são colocadas as balizas que têm norteado as análises de um grupo de pesquisadores do HISTEDBR de Mato Grosso do Sul, organizado em torno de investigação que tem como objeto os instrumentos do trabalho didático na escola moderna brasileira. Até o momento, o foco privilegiado tem sido o ensino secundário, sobretudo em sua forma mais desenvolvida encarnada pelo Colégio Pedro II, pois no período estudado, envolvendo o Império e as décadas iniciais da Primeira República, esse estabelecimento escolar era modelo para os demais no Brasil. São tomados como elementos de demonstração os dois principais manuais didáticos de História do Brasil do período, escritos por professores desse colégio ainda durante o Império e que tiveram expressiva circulação até as primeiras décadas da época republicana.

Do ponto de vista teórico-metodológico, a análise do manual didático considera previamente o próprio movimento do trabalho no âmbito da produção capitalista, pois corresponde ao seu continente. O trabalho didático, sob essa ótica, é entendido como a forma concreta pela qual se realiza o trabalho na escola moderna e algo submetido ao 
referido movimento geral. Em linhas gerais, precisa ser levada em conta a transição do artesanato feudal para a manufatura capitalista e, em seguida e sucessivamente, para a fábrica moderna e para a fábrica automatizada. Daí ser fundamental o domínio da proposta comeniana, pois revela ter sido a escola moderna concebida no interior de uma matriz manufatureira, representando, portanto, a superação da relação educativa feudal e de todos os elementos constitutivos da organização do trabalho didático correspondente. Superados estavam, portanto, o mestre, o discípulo, as fontes do conhecimento e outros recursos pedagógicos até então explorados, os procedimentos individuais de ensino e o espaço físico a eles associados.

Pensados a partir da divisão do trabalho, segundo a organização técnica da manufatura, os manuais didáticos comenianos realizavam a tendência de especialização dos instrumentos de trabalho, à época tão sensível no âmbito das oficinas manufatureiras. Se nessas oficinas os instrumentos ganhavam as formas mais adequadas à execução rápida das operações em que eram empregados e diversificavam-se, na escola moderna os manuais foram reproduzidos em profusão, sendo cada modalidade direcionada ao emprego especializado numa única matéria e num único nível de escolarização. Em Didáctica Magna, Comenius ilustra o imenso esforço, que ele próprio compartilhou, necessário à produção de uma enorme quantidade de manuais didáticos, segundo instruções oferecidas aos compendiadores para atender aos novos requisitos da escola moderna ${ }^{5}$. Com isso, ele contribuiu diretamente para dar consequiência ao seu projeto de objetivação do trabalho didático. Desencadeou e deu curso, dessa forma, a um movimento que começava a submeter o professor - o trabalhador no âmbito da escola moderna - ao instrumento de trabalho. Esse movimento decorreu e não pode ser dissociado da simplificação e da objetivação do trabalho, que, então, repousavam na divisão do trabalho e na emergência de instrumentos como os manuais didáticos. Estes passavam a ser os recursos materiais que, ao garantirem a transmissão do conhecimento, tiravam das mãos do mestre essa função, patente outrora na educação feudal, cuja base técnica era de natureza artesanal.

Chama atenção o fato de a forma histórica de organização do trabalho didático concebida por Comenius, no século XVII, ter sofrido um processo de cristalização, em seguida, tornando-se impermeável a mudanças mais profundas. Assim chegou aos nossos dias, o que lhe empresta uma característica anacrônica se forem consideradas as necessidades educacionais de hoje e os recursos tecnológicos disponíveis para atendê-las em outro patamar. Como o manual didático, na proposta comeniana, é a tecnologia educacional que articula a organização manufatureira do trabalho didático, também ele está marcado pelo anacronismo e já se torna tardia a sua superação.

A análise do manual didático precisa ser realizada incorporando tal consciência do limite histórico desse instrumento. E, para revelar toda a complexidade da relação educativa sustentada na organização manufatureira do trabalho didático, é essencial que opere em duas frentes. Por um lado, precisa evidenciar as características e o mérito dos conteúdos veiculados por esse instrumento de trabalho e, por outro, apreender as funções por ele assumidas na relação educativa.

Como este trabalho confere centralidade à área de História do Brasil, acentue-se que, ao lado de Corografia do Brasil, de Geografia do Brasil e de Literatura Brasileira, ela contribui para revelar como se iniciou o processo de produção de manuais didáticos no País. Enquanto tendência, as demais áreas, após a Independência, continuaram a utilizar manuais didáticos estrangeiros, difundidos desde a época colonial. Eram manuais portugueses e franceses, em especial. A Independência gerou, repentinamente, a necessidade de um tipo de conhecimento que reinterpretasse a história do Brasil a partir de interesses patrióticos, contribuindo para lastrear o processo de "invenção das tradições" 
nacionais. Nesse movimento, começaram a ser produzidos compêndios de literatura brasileira, de história, de geografia e de corografia do Brasil. Mesmo nessas áreas, contudo, os primeiros manuais não foram escritos em português, além de terem sido editados no exterior.

Na França surgiu, por exemplo, Resumé de l'histoire du Brésil, de Ferdinand Denis, traduzido em seguida pelo militar de origem portuguesa Henrique Luiz de Niemeyer Bellegarde. Foi publicado em 1831 com o título de Resumo de História do Brasil até 1828. Não se tratava de uma tradução literal, pois o texto em português foi "corrigido e aumentado", segundo a folha de rosto, iniciativa que granjeou encômios da Revista do $I H G B$ e de Sacramento Blake (Cf. Gasparello, 2002, n.p.).

No Brasil, o processo de produção de manuais didáticos nas áreas em referência, portanto, se iniciou pelo esforço de tradução de raras obras já existentes. Não existiu, imediatamente após a Independência, a preocupação de se produzir textos originais.

O livro de Bellegarde tornou-se o primeiro manual didático de História do Brasil no Colégio Pedro II, pois obteve autorização de Antonio Carlos de Andrada, Ministro do Império, para ser utilizado nesse estabelecimento escolar a partir de 1841. Ao expor a razão da tarefa que empreendera, o autor expressou a esperança de ver sua obra colocada a serviço da formação dos estudantes brasileiros: "feliz se nossos jovens compatriotas acharem n'este livro auxílio a seus primários estudos, único incentivo que a tal publicação nos animou." (Bellegarde, 1931, p. 253)

No levantamento dos programas de ensino do Colégio Pedro II, realizado por Vechia e Lorenz (1998, 406 p.), esse manual não foi flagrado. A primeira referência incide sobre o Compendio da historia do Brasil, escrito pelo General José Ignácio de Abreu Lima (1843, 2 v.). Filho do Padre Roma, líder e mártir da Revolução Pernambucana, Abreu e Lima foi uma figura fascinante, um homem nutrido nos ideais republicanos, um herói romântico que cerrou fileiras no exército libertador de Bolívar. O Brasil, recém saído da condição de colônia e sem ter ainda a sua história escrita, moveu o sentimento patriótico do autor, que resolveu compor um sintético compêndio e contar a história da nação recémindependente. Não há indícios de que o livro tenha sido pensado, originalmente, como recurso de apoio ao trabalho didático. Mas a sua segunda edição, publicada no mesmo ano da primeira, já levava em consideração o mercado escolar, daí ter sido escoimada de anexos documentais e notas, concentrando o texto num único volume. Esse livro, à época, foi alvejado pelas restrições do Instituto Histórico e Geográfico Brasileiro, entidade oficial que se imbuíra da função, dentre outras, de legitimar exclusivamente pela sua sanção tudo o que fosse produzido nas áreas de História e de Geografia do Brasil. No caso em foco, parece, a postura do IHGB não resultara de crítica serena. Um biógrafo de Abreu e Lima a interpreta como reação do "exaltado lusófilo Varnhagen" para "advertir" contra o "perigo da nossa história ser escrita por nacionalistas" (Chacon, 1981, p. 111). Dois anos mais tarde, ao editar o seu segundo livro, Synopsis ou deducção chronologica dos factos mais notaveis da Historia do Brasil, Abreu e Lima augurou que ele não tivesse "a sorte" do primeiro, atingido pela "terrível fouce do Instituto histórico" (Lima, 1845, p. 448).

Também por força de seu caráter inédito, mesmo não tendo sido escrito com intenções didáticas e a despeito das restrições do IHGB, o Compendio da historia do Brasil foi recomendado para a disciplina correspondente nos programas do Colégio Pedro II aprovados em 1856, 1858 e 1862. Nos dois primeiros constituiu-se fonte exclusiva; no último conviveu com "postilas do Professor" (Vechia e Lorenz, 1998, p. 35, 49 e 66).

Sucedeu-lhe o manual Lições de História do Brasil para uso das escolas de instrucção primaria (Macedo, 1913, 519 p.), "adoptado pelo Conselho Superior da Instrucção publica". Seu autor, Joaquim Manoel de Macedo ${ }^{7}$, foi médico, poeta, 
romancista e historiador. Nessa última condição integrou os quadros do Instituto Histórico e Geográfico Brasileiro. Ao presente trabalho interessa, sobretudo, o fato de ter exercido a função de professor de "Historia e chorographia patria do antigo Collegio de Pedro II" (Id., ibid., folha de rosto), na qual foi entronizado em 1849 (Azevedo, 1921, p. 381). O exercício do magistério motivou Macedo a elaborar o referido manual de História do Brasil, possivelmente originário das "postilas" relacionadas nos programas de 1862. Em seguida, até o final da década de $1870^{8}$ (Vechia e Lorenz, 1998, p. 79 e 91), dominou o ensino de História do Brasil no estabelecimento escolar em referência. Como resultado do esforço de sistematização de seu autor, ganhou a condição de instrumento pioneiro, pois foi o primeiro manual intencionalmente produzido com finalidade didática na área.

Homônimo do anterior e também escrito com finalidade didática, Lições de Historia do Brazil (Maia, s.d., 346 p.) foi outro manual da área utilizado no Colégio Pedro II. O seu autor, Luis de Queirós Mattoso Maia, foi qualificado na Relação dos Professores do Collegio Pedro II de 1838 a 1920 (Azevedo, 1921, p. 382) como "professor cathedratico" de "Historia Geral". O mesmo documento assinalou, ainda, 1879 como o ano de sua posse. Constitui-se uma lacuna o fato de não ter sido registrado como professor de História do Brasil, pois, em 1882, mesmo ano da morte de Macedo, pela vez primeira o manual de Mattoso Maia já aparecia recomendado no programa correspondente do colégio da Corte, o que se repetiu, após a instauração da república, nos programas de 1892, 1893, 1895 e 1898 (Vechia e Lorenz, 1998, p. 108, 123, 143, 158 e 180) ${ }^{9}$. O final da última lição, exclusivo da primeira edição, é elucidativo, pois nele Maia assume, explicitamente, a condição de professor de História do Brasil junto aos colegiais do regime de Internato ${ }^{10}$ (Maia, a1882, p. 321).

Dos manuais utilizados no Colégio Pedro II ao longo do período imperial, o mais difundido para além dos muros desse estabelecimento escolar foi o de Joaquim Manoel de Macedo. Até 1905, tal manual compunha-se de trinta e nove lições ${ }^{11}$. Nesse ano, ao ser publicada a sua décima edição, uma "Advertencia" assinada por Olavo Bilac foi nela incluída. Informa que o editor lhe encarregara de "completar este compendio", o que cumprira de forma a "respeitar o plano adoptado pelo seu autor".

Se consideradas as prescrições de Comenius, as características imanentes aos quatro textos referidos são pouco compatíveis com as do manual didático da escola moderna. São textos extensos, envolvendo lições com nível informativo detalhado e denso, o que termina por conferir um alentado volume aos livros. Mesmo o de Macedo, a despeito de comportar questionários e quadros sinóticos, não escapa dessa consideração. $\mathrm{O}$ de Bellegarde se desenvolve ao longo de 260 páginas. O de Abreu e Lima inclui dois volumes, com 324 e 200 páginas $^{12}$, respectivamente. O manual de Macedo contém 519 páginas, enquanto o de Mattoso Maia $346^{13}$. Outra característica que os distanciam dos modernos manuais didáticos comenianos é a despreocupação com as ilustrações. Todos os livros relacionados não as exploram ao longo das lições ou dos capítulos que os integram.

$\mathrm{O}$ grupo de pesquisa que vem investigando os instrumentos do trabalho didático na escola moderna tem se preocupado não com a análise exaustiva dos conteúdos dos manuais, optando por eleger temáticas específicas visando à verticalização da análise, a ponto de permitir a construção de juízos sobre o mérito do conteúdo.

Tomando como referência o caso da História do Brasil, foi realizado um primeiro exercício sobre como foi tratada a Guerra da Tríplice Aliança (1864-1870) nos manuais didáticos até o início do século XX. Esse evento, a par de sua relevância histórica para Mato Grosso do Sul e para o Brasil, sempre alimentou controvérsias. Necessariamente, a análise precisa levar em consideração a própria historiografia especializada referente ao conflito. No Brasil, essa historiografia pode ser enquadrada em duas tendências ao longo 
do tempo. A primeira, hegemonizada pela interpretação dos historiadores militares, foi dominante até a década de 1960. Circunscrita, de início, às memórias dos combatentes e aos relatórios de campanha dos oficiais, em seguida assistiu ao despontar das obras de síntese de historiadores militares como Tasso Fragoso (1956-1960, 5 v.). A segunda tendência emergiu no final da década de 1960, envolvendo estudiosos argentinos, uruguaios e brasileiros, como Leon Pomer (1980), Vivian Trias (1975), Eduardo Galeano (1978) e Júlio Chiavenato (s.d.). Teve a virtude de mostrar o lado universal de um conflito até então visto como de âmbito local, ao destacar suas determinações econômicas gerais atadas à dinâmica da sociedade capitalista, no século XIX, e à mediação política exercida pela Inglaterra, a potência econômica mais avançada à época. Alguns consideram ter sido inaugurada uma terceira tendência, configurada em estudos recentes que pretendem construir uma "nova história da guerra". Nascentes na passagem da década de 1980 para a de 1990, dentre eles ganharam realce o de Francisco Doratioto (2002). A pretexto de corrigir os desacertos explicativos da tendência anterior, decorrentes do nacionalismo e da teoria da dependência, o que é certo, parece que essa tendência, justificando-se na necessidade de renovar os estudos historiográficos, acabou por recolocar em primeiro plano as velhas querelas locais para explicar o conflito, circunscrevendo suas análises, sobretudo, à instância política. Nesse aspecto, se aproxima da versão produzida pela história militar, a despeito de seu discurso mais acadêmico.

Por força do período analisado, a exposição subseqüente cinge-se à primeira tendência, nascida na área de história militar, pois somente ela influenciou a elaboração dos manuais didáticos ora tratados ${ }^{14}$. Essa influência perdurou desde o último quartel do século XIX avançando até a primeira metade do século XX. Começou a ser produzida logo após o conflito e absorveu o discurso de suas fontes documentais angulares: os diários de campanha dos comandantes militares e as memórias de soldados envolvidos no conflito ${ }^{15}$. Na seqüência, essa tendência ganhou em sistematização e reforçou-se com a proeminência alcançada por obras de caráter sintético de historiadores militares, entre as quais desponta História da Guerra entre a Tríplice Aliança e o Paraguai (Fragoso, 1956-1960, 5 v.). Por transposição, a interpretação assim construída constituiu-se por décadas na versão dominante também em outros âmbitos. Consagrou-se, inclusive, dentro do Instituto Histórico e Geográfico Brasileiro. Portanto, a interpretação histórica desse conflito, no seu sentido mais amplo, erigiu-se como um decalque daquela elaborada no campo da história militar. Ganhou uma forma ufanista, pois muito marcada pelos traços característicos de uma instituição cujos créditos amealhados nos campos de batalhas lhe asseguraram papel de notável importância no sentido de imprimir no povo o sentimento de nacionalidade. $\mathrm{O}$ ufanismo foi um recurso não desprezível, por meio do qual as forças armadas deram conseqüência a um trabalho educativo de caráter cívico, que visava assegurar coesão aos brasileiros ${ }^{16}$.

Do ponto de vista epistemológico, o discurso dessa tendência historiográfica foi lastreado pelo positivismo, que, desde o século XIX, tivera quadros proeminentes dentro das forças armadas ${ }^{17}$. Daí, inclusive, a historiografia decorrente ter consagrado, nesse período, o fazer científico segundo os cânones dessa matriz teórica. Integram-na obras descritivas cujo discurso preconiza, como condição de rigor, a neutralidade e o distanciamento do pesquisador em face do objeto de investigação, mas, ao mesmo tempo, se move por um acendrado patriotismo e pela devoção incondicional à nação.

Ao longo do século XIX, a maioria dos manuais de História do Brasil utilizados no Colégio Pedro II pouco se destacou pela análise da Guerra da Tríplice Aliança. Os dois primeiros, de Bellegarde e de Abreu e Lima, nem poderiam ter se reportado ao conflito, pois foram editados anteriormente. Mas quando os demais, por força de atualizações 
recebidas, contaram o conflito, reproduziram a tendência dominante no final do século XIX e primeiras décadas do século XX, pois plasmaram a interpretação no discurso das memórias dos soldados e nos documentos oficiais da campanha. Foi o que se patenteou, por exemplo, no manual didático de Joaquim Manuel de Macedo.

No que se refere à Guerra da Tríplice Aliança ${ }^{18}$, esse livro descreveu os episódios militares em ordem cronológica, de forma a realçar a bravura dos principais comandantes e soldados brasileiros. Quanto às causas do conflito, ignorou quaisquer determinações que não as veiculadas oficialmente pela diplomacia brasileira, pelos relatórios de campanha e pelas memórias dos veteranos. A recusa à arbitragem paraguaia para o conflito entre o Brasil e Uruguai teria sido a causa principal da hostilidade de Solano Lopez. Logo, a motivação da guerra teria se inscrito na instância política e se resumiria às desavenças locais dos mandatários das vizinhas nações platinas.

Os antecedentes da Guerra do Paraguai começam a ser desenvolvidos na Lição XLIII, que trata do conflito entre o Brasil e o Uruguai. Solano Lopez teria procurado "impôr a sua mediação" para resolvê-lo. A recusa teria motivado uma "nota insolente" de sua lavra, datada de 30.08.1864, "communicando considerar a occupação do Estado Oriental como um attentado contra a independencia d'essa nação, e como um perigo para o Paraguay" (Macedo, 1913, p. 393).

A 12.11.1864 teve lugar a "inesperada e brutal aggressão", representada pelo aprisionamento do "paquete brasileiro Márquez de Olinda" em águas do Rio Paraguai. Esta embarcação conduzia com destino a Cuiabá o presidente da Província de Mato Grosso, coronel Francisco Carneiro de Campos (Macedo, 1913, p. 393-4).

Ainda nesse capítulo começa a descrição dos episódios da conflagração armada. Vão sendo referidos em ordem cronológica e, às vezes, chegam às minúcias das estratégias e táticas militares adotadas. Em nenhum momento são feitos quaisquer destaques que não os exclusivamente ligados aos campos de batalhas. Os episódios referentes às derrotas do exército nacional são minimizados, sobrepondo-se uma interpretação idealizada que realça os atos de bravura de militares brasileiros envolvidos. Nas condições mais desfavoráveis, teriam eles realizado proezas magníficas e heróicas. Às vezes, os adjetivos utilizados chegam a ser ostensivamente impróprios. No caso da tomada do Forte Coimbra, o comandante brasileiro, "tenente-coronel Hermenegildo Porto Carrero, tinha apenas 115 soldados de guarnição, 17 galés, e alguns indios." Seis mil soldados paraguaios o assaltaram sob o comando do General Barrios. "Porto Carrero, e essa pequena guarnição, resistiram heroicamente, conseguindo repellir trez investidas do inimigo, e, durante a noite de 28, realisando uma feliz retirada." (Macedo, 1913, p. 394, grifo nosso). O desastrado evento da Retirada da Laguna teria sido "uma estupenda epopéa de bravura, de soffrimentos e de provações." (Macedo, 1913, p. 395, grifo nosso)

Esse é o tom da descrição também nas três lições subseqüentes, que desenvolvem em detalhes todos os episódios militares após a assinatura do Tratado da Tríplice Aliança. É indisfarçável o ufanismo que cerca a análise. As tropas brasileiras, segundo o texto do manual, tiveram participação decisiva nos combates. Na Batalha do Riachuelo, travada a 11.06.1865, por exemplo, deram "uma victoria retumbante aos exercitos aliados" (Macedo, 1913, p. 401). "A Jequitinhonha, apezar de encalhada, combateu heroicamente (...). E a Parnahyba, cercada e abordada por trez navios ao mesmo tempo, e defendendo-se com inenarrável bravura, concorreu grandemente para o resultado da acção." (Macedo, 1913, p. 402)

A patriotice chega a alimentar a idéia de superioridade brasileira em face de argentinos e uruguaios, notória nas descrições que relatam e enfatizam episódios de vitórias do aguerrido exército nacional e derrotas dos aliados. O forte de Curuzú, atacado a 
$1^{\circ}$. de setembro de 1866, "exclusivamente pelas forças do Brasil, sem o concurso dos alliados", rendeu-se três dias depois. Enquanto isso, o ataque realizado por Mitre ao Forte Curupaity, a 22 de setembro do mesmo ano, "foi um desastre. A batalha durou dez horas, e os exercitos alliados retiraram-se derrotados", com perda de 4.000 soldados dos 23.000 combatentes (Macedo, 1913, p. 404).

A superioridade das tropas brasileiras e de seu comando é cantada, igualmente, em outros passos do manual. Existiam "dissenções (...) entre os chefes dos exercitos aliados. Para salvar a situação, o governo imperial nomeou commandante geral das forças brasileiras o marquez de Caxias", que assumiu o posto a 28.11.1866. Caxias teria disciplinado e reconstituído o exército, além de ter desencadeado um "ultimo periodo da campanha do Paraguay" em que "a lucta contra Lopez foi quasi exclusivamente sustentada pelo Brasil" (Macedo, 1913, p. 409).

Depois de recusar uma "nova proposta de paz" de Solano Lopez, Caxias iniciou a execução de seu "plano de campanha: chegar até Humaytá, cercar o inimigo, interceptando todos os recursos que lhes pudessem vir de Assumpção e do interior, e obrigal-o a aceitar uma batalha decisiva." "Tal plano teria sido cumprido "com felicidade". Os combates vão sendo descritos um a um: Tuyucué, o passo de Curupaity, Potrero Ovelha, Tahy e Tuyuty. Neste último, os paraguaios, "logo na primeira investida, conseguiram derrotar os contingentes argentinos; mas o general brasileiro visconde de Porto Alegre repelliu-os, havendo elles deixado quasi dois mil cadaveres no campo de batalha." (Macedo, 1913, p. 410)

Em 19.02.1868 a esquadra brasileira forçou a passagem de Humaitá. "Esta victoria" foi decisiva e "uma das mais importantes de toda a campanha", culminando com o assédio a Assumpção. "Lopez retirou-se (...) e foi fortificar-se em Tebicuary". Outras batalhas foram vencidas na seqüência pelo exército brasileiro, como Laureles. Humaitá rendeu-se a 5 de agosto. Começou então a perseguição a Lopez, que "seguira de Tebicuary para Piquiciry, onde se entricheirara." Os combates concentraram-se nos "terrenos pantanosos do Chaco". Os brasileiros sairam-se vencedores nas "memoraveis batalhas de Itororó, Avahy, Lomas Valentinas e Angostura.” (Macedo, 1913, p. 410-1)

Em fuga, Lopes viu a entrada dos adversários em Assunção e foi acumulando derrotas sucessivas: Jejuy, tomada de Sapucaia, Perebebuy, batalha de Campo Grande, Naranjahy e, por fim, "Cerro Cora, ás margens do arroio Aquidaban, perto da fronteira de Matto Grosso", onde morreu "o ditador do Paraguay, a 1 de março de 1870." (Macedo, 1913, p. 418)

O atrelamento da versão do manual didático às memórias dos combatentes e aos documentos oficiais é sempre patente. No passo em que conta os momentos finais de vida de Solano Lopez, usa o próprio relatório do general Câmara, comandante do último assalto da Guerra.

Lopez, abandonando-se á fuga, lançou-se para o interior do matto, até que ferido, desanimado, exhausto, apeando-se do seu Cavallo, dirigiu-se para aquelle arroio [Aquidaban] que tentou transpor, cahindo de joelhos na barranca opposta. Foi nessa posição que, tendo-me apeiado e seguido em seu encalço, o encontrei. Intimei-lhe que se rendesse e entregasse a espada, que o general que commandava aquellas forças lhe garantia os restos de vida. Respondeu-me atirando um golpe de espada. Ordenei então a um soldado que o desarmasse, acto que foi executado ao tempo em que exhalava o ultimo suspiro. (Apud Macedo, 1913, p. 419)

Em resumo, ao recontar a guerra, o manual didático de Macedo fez extensos relatos das principais batalhas da campanha contra o Paraguai. Esmerou-se nas descrições 
detalhadas de estratégias e táticas militares empregadas em alguns dos episódios bélicos mais significativos. Reproduziu as informações como se decalques fossem dos documentos oficiais e das versões disseminadas pelas memórias dos combatentes.

A primeira edição do manual Lições de História do Brasil, escrito por Mattoso Maia, compunha-se originalmente de 37 lições, concluindo a análise com a proclamação da maioridade de D. Pedro II, em 23 de julho de 1840. Em seguida, um apêndice denominado "Organisações Ministeriaes no Brazil" relacionava os ministérios e seus integrantes, desde a retirada de D. João VI até o designado em 28 de março de 1880. Portanto, a edição consultada foi publicada após essa data, o que permite concluir ter ocorrido uma lacuna de quarenta anos de história sem análise. A Guerra da Tríplice Aliança aconteceu exatamente dentro desse lapso. Tal lacuna era compreensível nas primeiras edições do manual de Macedo, pois, à época, o conflito ainda não era assunto obrigatório nos programas do Colégio Pedro II. A mesma justificativa poderia se aplicar às primeiras edições do livro de Mattoso Maia, anteriores a 1882. Depois, não mais, pois nos programas desse mesmo ano a unidade 35 de "Historia e Chorographia do Brazil" passou a incluir os seguintes tópicos: "Guerra contra a Banda Oriental na Republica Oriental do Uruguay, 1864 a 1865. Intervenção indebita do dictador Francisco Solano Lopez. Guerra contra o Paraguay, 18641870" (Vechia e Lorenz, 1998, p. 108). É possível que a tardia inclusão da matéria nos programas do Colégio Pedro II, patente por decorrência nas primeiras edições dos manuais de Macedo e de Mattoso Maia, tenha sido motivada pelo princípio positivista que recomendava o distanciamento no tempo para a análise científica serena e neutra dos eventos sociais.

No ano de 1886, ajustando-se às determinações dos programas do Colégio Pedro II, o manual de Mattoso Maia também passou por atualização e incluiu o grande conflito platino em seu conteúdo. Quanto à substância, a análise em tudo é convergente com a desenvolvida no manual de Macedo, por força do detalhamento dos assuntos em grande parte coincidente, pois determinado pelo programa de História do Brasil do Colégio Pedro II, e das fontes comuns que nutriram as interpretações, além do estilo marcado por adjetivação retumbante. Daí ser dispensável a repetição. Uma curiosidade apenas merece registro: Mattoso Maia era veterano da guerra, o que lhe permitiu emprestar a autoridade de seu testemunho pessoal, em alguns passos do livro, para evidenciar a fidedignidade de certos fatos relacionados ao conflito ${ }^{20}$.

Dois séculos depois de edificada a obra pedagógica comeniana, no Colégio Pedro II os manuais didáticos ainda estavam muito aquém do exercício da função que o bispo morávio lhes conferira. Para ilustrar, são discutidas as implicações, quanto à organização do trabalho didático, da função exercida por esses instrumentos na relação educativa.

Além de destituídos de recursos técnicos para facilitar a aprendizagem dos estudantes, tanto no que se refere à forma rebuscada quanto no que concerne ao extenso conteúdo das lições, os primeiros manuais, escritos respectivamente por Bellegarde e por Abreu e Lima não revelam preocupações de caráter pedagógico. É compreensível, pois não foram produzidos com a intenção de atender requisitos imanentes ao trabalho didático. Bellegarde, mesmo preocupado com a educação dos "jovens compatriotas" e afirmando ter produzido um "livro [de] auxílio a seus primarios estudos" (Bellegarde, 1831, p. 253), pouco acrescentou à tradução de uma obra sintética francesa já disponível no mercado, ela própria despreocupada com questões de ordem pedagógica. Quanto a Abreu Lima, preocupava-se, sim, com o fato de inexistir um livro de síntese histórica que contasse a todos os brasileiros os acontecimentos do passado com base nos interesses da nação recémindependente. Na seqüência, a sua utilização como manual didático de História do Brasil no Colégio Pedro II ocorreu, tão somente, por ser uma das duas alternativas disponíveis no 
mercado, talvez julgada preferível por ter sido produzida por autor brasileiro. Certo é que, por força da expressão conquistada pelas escolas no mercado de livros, a segunda edição do texto de Abreu Lima, em um único volume, veio à luz liberada dos anexos documentais e de notas, tornando o produto mais barato e acessível aos jovens colegiais.

Foi outra a forma de organização que presidiu à elaboração do primeiro manual de História do Brasil produzido e utilizado por um professor do Colégio Pedro II. Do ponto de vista especificamente didático, chamam a atenção os recursos incorporados ao conteúdo de Lições de Historia do Brasil. A cada lição deveriam seguir-se, primeiro, um glossário de termos e expressões que lhe é específico, denominado "explicações" ${ }^{21}$, depois um quadro sinótico dos principais "feitos e acontecimentos", associando-os aos seus "personagens e corporações" e aos seus "atributos", e, por fim, um rol de "perguntas", que orientaria o professor quanto à verificação da aprendizagem e o aluno, em correspondência, quanto ao que deveria ser memorizado.

Esse manual, escrito por Joaquim Manoel de Macedo, ainda apresenta alentado número de páginas para um instrumento de trabalho dessa natureza. Mas a Prefação da Primeira Edição procura demonstrar que não é tão extenso quanto aparenta.

Uma obra escripta para servir ao estudo de meninos não deve ser longa, e o nosso compendio á primeira vista desagradará pela sua apparente extensão; affigura-se-nos porém que um rapido exame do livro demonstrará que este só avulta pelas explicações, pelos quadros synopticos e pelas perguntas que seguem ás lições com o fim de facilitalas, e de graval-as na memoria dos discipulos. (Macedo, 1913, n.p.)

Realça, em seguida, que esses três recursos estão a serviço do método: "ora é exactamente nas explicações, nas perguntas, e nos quadros synopticos annexos ás lições, que se encontram as bases principaes do methodo que adoptámos."

O manual didático, pensado pelo autor sobre fundamentos ainda distantes da concepção comeniana, só ganharia vida pela intervenção qualificada e consciente do professor: “(...) especialmente nas escolas de instrucção primaria o professor é a alma do livro, e não ha methodo que aproveite, se o professor não lhe dá vida, applicando-o com paciencia e consciencia no ensino." (Macedo, 1913, loc. cit.) Essa centralidade do professor na atividade didática foi uma idéia amplamente difundida no Brasil oitocentista, corroborada pelo grosso das análises educacionais então realizadas ${ }^{22}$.

No processo de aprendizagem, a faculdade intelectual mais requerida do estudante era a memória. Seu esforço se resumiria, em grande parte, à memorização das informações pertinentes às respostas ao questionário e ao quadro sinótico, que giravam em torno das batalhas, das suas datas e de seus heróis. O discurso do instrumento de trabalho reitera que o professor deveria ir, nas suas explanações, além do conteúdo do manual didático.

Um menino que tem decorado uma lição nem por isso sabe a lição; para que a saiba é indispensavel que comprehenda o que exprimem, o que significam as palavras que repetio de cor; por esta razão anexamos no nosso compendio a cada lição algumas explicações, que o professor deve completar ajuntando a essas tantas outras quantas forem necessarias.

Depois de bem comprehendida assim a lição, as perguntas destacadas põem em proveitoso tributo a attenção e a reflexão dos meninos, e emfim o quadro synoptico que elles devem reproduzir de cor na pedra e no papel, grava na memoria toda a matéria estudada. (Macedo, 1913, loc. cit.)

Esse manual pode ser entendido como uma manifestação típica do ensino secundário à época do Império, em especial quando a referência é aquele conjunto de 
disciplinas voltado ao conhecimento do Brasil: história, geografia, corografia e literatura brasileira. Atado às tradições legadas pela Contra-Reforma, o Brasil ainda não explorara mais extensamente os manuais didáticos modernos. Esses instrumentos do trabalho didático, tão valorizados por educadores como Ratke (2008, 233 p.) e Comenius, haviam alcançado elevado grau de especialização, tanto no que se refere aos níveis de ensino quanto às séries dentro de um mesmo nível de ensino. Assim simplificados, tornaram-se necessários, sobretudo, no interior daquele grande movimento de difusão da escola moderna, que alcançara maior intensidade em territórios dominados pela Reforma protestante. Lá, por força da elevada demanda por educação, os manuais didáticos deram suporte a uma situação de carência, quando não havia, inclusive, número razoável de professores que pudesse assumir a atividade de ensino. Daí Comenius ter depositado no instrumento de trabalho a garantia da transmissão do conhecimento.

Não era isto o que ocorria no Brasil, onde a expansão escolar não ganhara intensidade. Menos ainda no ensino secundário, que, entre as marcas de seu elitismo, recrutava professores junto aos mais celebrados conhecedores das matérias ensinadas. Se não dispunham de qualquer formação pedagógica anterior, eram padres e profissionais liberais, como médicos, advogados e engenheiros, que constituíam o corpo dos quadros intelectuais mais preparados do Império. Tanto é assim que, por "falta de livros especiaes"23, se dispunham a escrever os textos didáticos para as disciplinas que ministravam. De início esses textos ganharam a forma de "postilas"24. Alguns, progressivamente aperfeiçoados, superaram-na e tornaram-se livros. Dessa forma nasceram os primeiros manuais de ensino secundário, entre nós, naquelas matérias que se aplicavam ao conhecimento do Brasil ${ }^{25}$. Os seus autores eram professores que, pelo domínio do conhecimento muito além da média, lembravam os educadores da época colonial, quando a divisão do trabalho didático mal começara a se insinuar (Alves, 2005, p. 56).

Em correspondência, a relação educativa determinada por esse quadro histórico se distanciava do que preconizara Comenius. Os manuais didáticos no Colégio Pedro II, elaborados por profissionais que, por formação, revelavam-se pouco aptos para articulá-los às suas especializadas destinações pedagógicas, eram livros que disputavam, ainda, o emprego em outros níveis de ensino e numa fatia do mercado que ia além da reduzida clientela escolar. Eles impactavam não só o público externo formado por estudiosos diletantes, mas tornavam-se fontes, inclusive, para os especialistas. Entre os manuais ora analisados, o de Joaquim Manoel de Macedo foi o mais expressivo, pois, mesmo depois de substituído como referência nos programas desse estabelecimento escolar, continuou recebendo sucessivas edições, tendo passado, inclusive, por uma atualização em $1905^{26}$. À época da Primeira República, muitos outros surgiram e continuaram sendo editados com as mesmas características. Talvez o exemplo mais significativo seja História do Brasil, de João Ribeiro $\left(1914,541\right.$ p.) ${ }^{27}$, amiúde referido nos ensaios e monografias de história e de ciências sociais produzidos na primeira metade do século XX.

Segundo a tendência já apontada, no estabelecimento escolar modelo também o manual de Macedo deve ter percorrido a trajetória da "postila" ao livro. Suas origens parecem remontar às "postilas" referidas nos programas de 1862. Sendo aperfeiçoadas ano a ano, atingiram certo grau de sistematização considerado compatível ao exercício mais permanente da função de manual didático, daí a decisão de dar-lhes a forma de livro. Depois de editado, passou a ser recomendado nos programas de ensino da década de 1870. Em favor dessa hipótese, vale relembrar o fato de Macedo ter começado a exercer o magistério no Colégio Pedro II em 1849. Outra forte evidência dessa possibilidade reside no fato de coincidirem os conteúdos das unidades do programa de História do Brasil e das lições do manual de Macedo. 
No que se refere ao manual didático de Mattoso Maia, ausentam-se as preocupações especificamente pedagógicas: nem quadros sinóticos com resumos das matérias incluídas nas lições nem questionários norteadores para professores e para alunos. Mas não se deduza daí qualquer dúvida sobre a finalidade especificamente pedagógica desse manual. Na versão referente à primeira edição, o último período da lição derradeira é elucidativo ao revelar os destinatários do livro: os colegiais.

Tendo chegado ao fim do nosso anno lectivo, cumpre-me agradecer-vos a attenção com que me tendes ouvido, e o vosso procedimento tanto n'esta aula, como na de Chorographia. - O muito que me falta para igualar ao provecto Professor do Externato na transmissão de suculentas e eruditas lições, tendes vós supprido com uma applicação constante nos vossos estudos, de forma que deveis apresentar resultados practicos de aproveitamento. Outra cousa tambem não era de esperar nem de vós, nem do regimen d'este Internato, confiado a tão proficiente Direcção, sob as vistas solicitas do Governo Imperial, e sob a protecção do mais Illustrado e Magnanimo dos Monarchas. (Maia, s.d, p. 321)

Chama a atenção o fato de Mattoso Maia ter produzido um manual didático, logo após sua entronização na docência de História do Brasil, quando já existia o de Macedo que ganhara larga difusão. A hipótese é a de que a iniciativa se associava à identificação subjetiva do professor com a atividade que realizava. Como a simplificação e a objetivação do trabalho didático eram incipientes no Brasil, ainda nessa fase, o professor se via como um mestre qualificado, que procurava imprimir a sua marca no resultado do trabalho. Para tanto, a elaboração de seu manual didático assomava como primordial iniciativa. Com esse recurso, o professor do Colégio Pedro II sentia-se no controle do trabalho didático, situação antagônica à que pensara Comenius ao conceber a escola moderna e a relação educativa que lhe particularizava.

Fora do Colégio Pedro II e em paralelo, ao final do Império e ao longo da Primeira República, outros manuais começaram a ser editados. Alguns já realizavam uma patente simplificação do conteúdo pela eliminação de detalhes informativos e explicações aprofundadas. Eram manuais como o exemplificado por Pequena História do Brazil por Perguntas e Respostas (Lacerda, 1887, 160 p.). Com dimensões menores e números de páginas bem mais reduzidos, o conteúdo era mais aligeirado. Alguns, como o referido, optavam por exposição de natureza catequética e já começavam a explorar ilustrações. A primeira impressão é a de que se destinavam ao nível de ensino anterior ao secundário. Com certeza isso ocorria também, mas, ainda nessa fase, os manuais eram utilizados em diversos níveis de ensino, no Brasil, o que denota uma limitação quanto ao grau atingido pela divisão do trabalho didático. Nas folhas de rosto de quase todos os compêndios tal imprecisão torna-se evidente. Ao definir a sua destinação, mesmo o manual de Joaquim Manuel de Macedo, elaborado para o ensino de História do Brasil no Colégio Pedro II, dizia: "para uso das escolas de ensino primario" (Macedo, 1913, página de rosto). A concepção de trabalho didático contribuía para acentuar a imprecisão. O professor ainda era visto como sua figura central, daí, como decorrência, a idéia de que, mesmo em nível de ensino anterior, tal tipo de manual poderia servir-lhe, pelo menos, como uma fonte alternativa de informação.

No próprio nível de ensino secundário, a expansão escolar conspirou contra os manuais assemelhados aos de Macedo e Mattoso Maia. Mesmo pouco impactante, pois circunscrita ao surgimento de liceus provinciais e alguns colégios particulares nas principais cidades do Brasil, fez o trabalho didático nesses estabelecimentos confluir para o uso sistemático de manuais mais parecidos com o de Lacerda. Diversas condições 
materiais favoráveis se conjugavam para favorecer e reforçar esse resultado. Tais instrumentos simplificavam o trabalho realizado pelo professor, o que facultava a incorporação ao magistério de quadros que não se destacavam por um domínio do conhecimento situado acima da média. Assim, viabilizavam o movimento de expansão escolar. Por outro lado, os volumes menores dos novos manuais e as quantidades vultosas de exemplares colocadas em circulação a cada edição, apresentavam a vantagem adicional de baratear seus preços, tornando-os mais acessíveis aos colegiais. Logo, por oposição aos livros elaborados por Macedo e Mattoso Maia, textos como o de Lacerda tornaram-se, eles próprios, a encarnação das novas condições materiais e pedagógicas favoráveis à disseminação do ensino secundário nos principais centros urbanos do País. $\mathrm{O}$ seu emprego e a sua disseminação denotavam que, enfim, o Brasil começava a enveredar, tardiamente, por uma rota de desenvolvimento da escola moderna coincidente com a solução dada por Comenius. Começava a se instaurar, entre nós, a forma manufatureira mais madura de organização do trabalho didático.

Dentro dos limites teóricos e documentais desta primeira abordagem dos manuais didáticos de História do Brasil, são resumidas, na sequiência, algumas conclusões sobre o seu conteúdo e o seu uso na relação educativa instaurada no Colégio Pedro II ao longo da época imperial e início da época republicana.

Do ponto de vista do conteúdo, quando recontaram a Guerra da Tríplice Aliança, esses manuais: a) se limitaram a incorporar a interpretação consagrada pela área de história militar, respaldada em fontes como os diários de campanha dos oficiais comandantes e as memórias dos combatentes; b) reduziram a descrição do conflito ao plano político, radicando suas causas nas desavenças diplomáticas dos vizinhos platinos e, quanto ao conflito propriamente dito, cingiram-se à descrição dos embates armados; c) do ponto de vista epistemológico, realizaram um discurso positivista pertinente às suas fontes, produzidas no seio da instituição que tivera papel de destaque na disseminação da doutrina no Brasil.

Quanto à sua função no trabalho didático, tais instrumentos subordinaram-se a uma concepção bastante distanciada da proposta de Comenius, pois implicava uma limitada incorporação da divisão do trabalho, cerceando a realização de um maior grau de simplificação e objetivação da atividade de ensino. Como decorrência, o professor era pensado como um profissional que exercia o controle do trabalho e de seus instrumentos.

Daí, também, o fato de, ao longo do século XIX, os manuais das disciplinas consagradas ao conhecimento do Brasil, no Colégio Pedro II, terem como autores, predominantemente, os seus próprios professores. Tais mestres eram figuras que detinham um grau de conhecimento muito acima da média. Ao escreverem livros didáticos, revelavam elevada identificação subjetiva com o seu trabalho e o seu domínio sobre as condições que o cercavam, distanciando-se do professor comeniano, mero executor de rotinas e procedimentos ditados pelo manual didático.

Em síntese e por consequiência, a organização do trabalho didático da escola moderna, no Brasil, encontrava-se num estágio muito aquém da concepção comeniana, ainda no início do século XX, situação explicável, em grande parte, pelo limitado grau atingido pela expansão escolar, em especial no nível de ensino secundário. Atendendo a clientela restrita, composta por filhos dos grandes proprietários rurais, de comerciantes e das nascentes, mas minguadas camadas médias urbanas, ao ensino secundário não se impôs a força de uma pedagogia imbuída dos recursos necessários para "ensinar tudo a todos". Mal se insinuava a determinação material que avassalaria, na seqüência, a incipiente divisão do trabalho didático existente, os instrumentos de trabalho e os procedimentos do professor, bem como, por decorrência, a relação educativa, cujas características e práticas, 
ainda atreladas às pedagogias da época colonial, pouco se conformavam às formas mais desenvolvidas da escola moderna.

\section{Referências}

ALVES, Gilberto Luiz. A Produção da Escola Pública Contemporânea. 4.ed. Campinas, SP: Autores Associados, 2006.

O Trabalho Didático na Escola Moderna: Formas Históricas. Campinas, SP: Autores Associados, 2005.

ARARIPE, Tristão de Alencar. Tasso Fragoso: um Pouco de História do Nosso Exército. Rio de Janeiro: Biblioteca do Exército, 1960.

AZEVEDO, Philadelpho de. Subsidios para a Historia do Collegio Pedro II. In:

Annuario do Collegio Pedro II: 1919-1920. Rio de Janeiro: Typ. da Revista dos

Tribunaes. v. 4, p. 379-84.

BANDEIRA, Manuel. Noções de História das Literaturas. São Paulo: Comp. Edit.

Nacional, 1954. v. 2.

BELLEGARDE, Henrique Luís de Niemeyer. Resumo de Historia do Brasil até 1828.

Traduzido de Mr. Denis, correcto e augmentado por H. L. de Niemeyer Bellegarde. Rio de Janeiro: Typ. Gueffier, 1831.

BITTENCOURT, Circe. Livro Didático e Saber Escolar: 1810-1910. Belo Horizonte, MG: Autêntica, 2008.

BONAZZI, Marisa e ECO, Humberto. Mentiras que Parecem Verdades. São Paulo: Summus, 1980.

CHACON, Vamireh. História das Idéias Socialistas no Brasil. 2.ed.rev.aument.

Fortaleza: Edições UFC; Rio de Janeiro: Civilização Brasileira, 1981.

CHIAVENATO, Julio José. Genocídio Americano: a Guerra do Paraguai. São Paulo: Círculo do Livro, s.d.

COMÉNIO, João Amós. Didáctica Magna: Tratado da Arte de Ensinar Tudo a Todos. 2.ed. Tradução de Joaquim Ferreira Gomes. Lisboa: Fundação Calouste Gulbenkian, 1976.

COUTO, Pedro do. Pontos de História do Brasil. 3.ed. Rio de Janeiro: Jacintho Ribeiro dos Santos, 1923.

DORATIOTO, Francisco. Maldita Guerra: Nova História sobre a Guerra do Paraguai. São Paulo: Companhia das Letras, 2002.

FERREIRA, Aurélio Buarque de Holanda. Novo Aurélio: Século XXI. 3.ed. Rio de Janeiro: Nova Fronteira, 1999.

FRAGOSO, Tasso. História da Guerra entre a Tríplice Aliança e o Paraguai. 2.ed. Rio de Janeiro: Biblioteca do Exército, 1956-1960. 5 v.

FREITAG, Bárbara; COSTA, Wanderly F. da e MOTTA, Valéria R. O Livro Didático em Questão. 2.ed. São Paulo: Cortez, 1997.

GALEANO, Eduardo. As Veias Abertas da América Latina. 4.ed. Tradução de Galeno de Freitas. Rio de Janeiro: Paz e terra, 1978. 
GASPARELLO, Arlette Medeiros. Historiografia Didática e Pesquisa no Ensino de História. Anais do X Encontro Regional de História da ANPUH: História e Biografias. Rio de Janeiro: Universidade do Estado do Rio de Janeiro, 2002. Www.rj.anpuh.org/anais/2002/comunicacoes. Acesso em 23.11.2008.

GATTI JÚNIOR, Décio. A Escrita Escolar da História: Livro Didático e Ensino no Brasil (1970-1990). Bauru, SP: EDUSC; Uberlândia, MG: Edufu, 2004.

HOLlANDA, Guy de. Um Quarto de Século de Programas e Compêndios de História para o Ensino Secundário Brasileiro: 1931-1956. Rio de Janeiro: MEC-INEP, 1957.

LACERDA, Joaquim Maria de. Pequena História do Brazil por Perguntas e Respostas. 6.ed. Rio de Janeiro: B. L. Garnier, 1887.

LIMA. J. I. de Abreu e. Compendio de Historia do Brasil. Rio de Janeiro: Eduardo \& Henrique Laemmert, 1843. 2 t.

LIMA. J. I. de Abreu e. Synopsis ou Deducção Chronologica dos Fatos Mais Notaveis da Historia do Brasil. Pernambuco: Typographia de M. F. de Faria, 1845.

LINS, Osman. Do Ideal e da Glória: Problemas Inculturais Brasileiros. São Paulo: Summus, 1977.

MACEDO, Joaquim Manoel de. Lições de Historia do Brasil para Uso das Escolas de Instrucção Primaria. Rio de Janeiro: B. L. Garnier; Paris: E. Belhate \& Cia., 1880.

Lições de Historia do Brasil para Uso das Escolas de Instrucção Primaria. Rio de Janeiro; Paris: Livraria Garnier, 1913.

MAIA, Luis de Queirós Mattoso. Lições de Historia do Brazil. Rio de Janeiro: Dias da Silva Junior, s.d.

Lições de Historia do Brazil. Rio de Janeiro: B. L. Garnier, 1886.

OLIVEIRA, A. de Almeida. O Ensino Público. Brasília: Senado Federal, 2003. (Edições do Senado Federal, 4)

POMER, León. A Guerra do Paraguai: a Grande Tragédia Rioplatense. Tradução de Yara Peres. São Paulo: Global, 1980. (Passado \& Presente, 7)

RATKE, Wolfgang. Escritos sobre A Nova Arte de Ensinar de ... (1571-1635): Textos Escolhidos. Tradução de Sandino Hoff. Campinas, SP: Autores Associados, 2008. (Clássicos da Educação)

RIBEIRO, João. História do Brasil. 5.ed.rev. Rio de Janeiro; São Paulo e Belo Horizonte: Francisco Alves \& Cia.; Paris e Lisboa: Aillaud, Alves e Cia., 1914.

História do Brasil. 20.ed.rev. Belo Horizonte; Rio de Janeiro: Itatiaia, 2001.

(Coleção Reconquista do Brasil, 222)

TAUNAY, Alfredo d'Escragnolle. A Retirada da Laguna: Episodio da Guerra do Paraguay. 10.ed. Tradução de Affonso d'Escragnolle Taunay. São Paulo; Cayeiras; Rio de Janeiro: Comp. Melhoramentos de S. Paulo, (1935?).

TRÍAS, Vivian. EI Paraguay de Francia EI Supremo a la Guerra de la Triple Alianza. Buenos Aires: Crisis, 1975. (Cuadernos de Crisis, 19)

VECHIA, Ariclê e LORENZ, Karl Michael (orgs.). Programa de Ensino da Escola Secundária Brasileira: 1850-1951. Curitiba: Ed. do Autor, 1998. 


\section{Notas}

* Trabalho produzido no interior do projeto de pesquisa $O$ manual didático como instrumento de trabalho nas escolas secundária e normal (1835-1945), desenvolvido com o apoio do CNPq.

1 Gasparello (2002) é outra estudiosa que merece ser mencionada por ter realizado esforço similar de investigação em face de período em grande parte coincidente com o abordado por Bittencourt.

${ }^{2}$ Por ser uma categoria central na discussão ora travada, deve ser explicitada a acepção atribuída à expressão organização do trabalho didático. No entendimento adotado ela incorpora: a) a relação histórica educadoreducando; b) a mediação exercida pelos procedimentos do professor, pelos conteúdos didáticos e pelas tecnologias educacionais c) e a materialidade espacial e arquitetônica onde tal relação se dá. (Alves, 2005, p. $10-1)$.

${ }^{3}$ Uma só coisa é de extraordinária importância, pois, se ela falta, pode tornar-se inútil toda a máquina, ou, se está presente, pode pô-la toda em movimento: uma provisão suficiente de livros pan-metódicos. (Coménio, 1976, p. 469)

${ }^{4}$ Não se deve dar aos alunos nenhuns outros livros, além dos de sua classe. (Coménio, 1976, p. 226)

${ }^{5}$ No que se refere ao ensino das línguas materna e latina, por exemplo, Comenius afirmava serem necessários quatro manuais: "O Vestíbulo" para a "idade infantil", "A Porta” para a "idade pueril", "O Palácio" para a "idade juvenil" e "O Tesouro" para a "idade viril". Depois de expor a natureza do conteúdo de cada um, discutiu os correspondentes "livros auxiliares (...) que ajudam a usar, de uma maneira mais rápida e com maior fruto, os livros didáticos". Eram eles o "vocabulário língua materna-latim e latim-língua materna", o "dicionário etimológico latim-língua materna", o "dicionário fraseológico língua materna-língua materna, latim-latim" e o ainda inexistente "prontuário universal” (Coménio, 1976, p. 336-41).

${ }^{6} \mathrm{O}$ original d'esta Obra hé por vezes inexacto; nos trabalhamos para que a traducção o não fosse. Todas as passagens que aqui se acharem nas primeiras épocas, estranhas ao Resumo francez, estão em D. de Goez, Rocha Pita, Madre de Deos, Ayres do Cazal, Lery, ou Southey.

Quanto á parte contemporanea que nos diz respeito, limitamo-nos á pura e ingenua exposição dos factos, por assim o exigir o plano deste Epitome. (Bellegarde. 1831, p. 7)

7 Joaquim Manoel de Macedo (1820-1882) nasceu e faleceu em Itaboraí, Província do Rio de Janeiro. Projetou-se sobretudo como romancista. Segundo Manuel Bandeira (1954, p. 93-4), dentre os seus romances A moreninha e $O$ moço loiro" tornaram-se os "mais populares". O primeiro, objeto de "numerosas edições", como todos os demais, "é uma história romanesca, sentimental até a pieguice, escrita sem grande atenção à forma literária. Reflete, porém, com verdade até certo ponto, as intrigas casamenteiras da sociedade burguesa do tempo."

${ }^{8}$ Esse manual foi recomendado explicitamente no programa de 1877 , mas pode ter sido relacionado, também, no de 1870, não localizado pelos autores do levantamento tomado como referência (Vechia e Lorenz, 1998, p. viii, nota 2).

${ }^{9}$ O programa de 1898 indicou, explicitamente, a 5 . edição do manual de Mattoso Maia. Em 1912 a disciplina História do Brasil não constou nos programas do Colégio Pedro II. No programa de 1915 foram recomendados os autores Escragnolle Dória e João Ribeiro, sem que fossem nomeados os títulos dos livros tomados como fontes (Vechia e Lorenz, 1998, p. 216).

${ }^{10}$ Os professores dos regimes de internato e de externato não eram necessariamente os mesmos. Macedo, na condição de "cathedratico" de História do Brasil, pode ter sido o "provecto Professor do Externato" referido ao final do livro de Maia (s.d., p. 321). Se assim for, ambos teriam convivido, por pouco tempo, como professores da mesma disciplina nesse estabelecimento escolar, um no regime de internato e o outro no de externato.

${ }^{11}$ Esse é o número de lições da quinta edição, publicada em 1880, pouco antes da morte do autor.

${ }^{12}$ No mesmo ano o livro foi objeto de uma segunda edição, escoimada de notas e da farta documentação contidas na primeira. Resultou um texto de 352 páginas. Com a iniciativa, o autor e a editora também levaram em conta um expressivo nicho de mercado que se abria, pois visaram, então, produzir um livro "mais adequado para os Colégios" (Cf. Gasparello, 2002, n.p.).

${ }^{13}$ São tomadas como parâmetros edições constantes das Referências Bibliográficas. 
14 Essa afirmação vale para a época imperial. Mesmo preponderante, tal tendência passou a comportar entendimentos parcialmente divergentes, após a proclamação da república, especialmente quanto aos móveis do conflito. Versões destoantes começaram a ser produzidas por alguns autores de manuais didáticos imbuídos do ideário republicano. Pedro do Coutto, professor do Colégio Pedro II, mesmo sem se afastar da interpretação mais geral que atribuía motivações locais ao conflito, o que o coloca no campo da tendência assinalada, se distanciou das análises dominantes ao afirmar categoricamente que a "guerra foi provocada e conduzida pelo Brasil." Reconheceu, inclusive, "a sanha de Pedro II" ao encetar, "por capricho", uma "perseguição tenaz a um homem", Solano Lopes, porque "lhe tinha ogeriza." (Couto, 1923, p. 12 e 13). João Ribeiro, igualmente professor do Colégio Pedro II, foi outra expressão desse tipo de análise. À semelhança de Pedro do Couto, contou os episódios da guerra da mesma forma que os outros manuais, mas, ao discutir os antecedentes do conflito, condenou a política brasileira de "supremacia sobre os estados do Sul" e a decorrente "immoralidade da nossa conducta", marcada por intervenções sistemáticas nos domínios dos vizinhos (Ribeiro, 1914, p. 512). Essas nuanças das análises difundidas por manuais didáticos poderão ser aprofundadas em estudos ulteriores, quando os textos elaborados ao longo da Primeira República forem examinados com maior profundidade.

${ }^{15}$ Uma dessas memórias ganhou celebridade e tornou-se, inclusive, sucesso editorial. Trata-se de A Retirada da Laguna, escrita pelo oficial de engenheiros da coluna que a realizou, Alfredo d'Escragnolle Taunay (1935?, 272 p.).

${ }^{16}$ Nesse processo, as lideranças militares começaram a desnudar, também, a omissão das classes dominantes no que se refere à sua participação na Guerra. Os detentores das grandes fortunas, no Brasil, furtaram-se ao envolvimento direto na frente de luta. Preferiram ser substituídos pelos seus escravos negros, que obtinham por esse meio a alforria.

${ }^{17}$ Quando se reporta à ebulição causada pelas idéias republicanas, desde as duas décadas anteriores a 1889, Tasso Fragoso, o autor da alentada História da Guerra da Tríplice Aliança e o Paraguai, evidencia explicitamente a sua simpatia pelo positivismo: "Um lustro antes da revolução republicana, houve vários incidentes na vida escolar, que testemunham a exaltação dos espíritos. Estive na Praia Vermelha durante êsse período, o que me faculta recordá-lo com conhecimento objetivo. Seguíamos com interêsse tôda agitação política que abalava a nação. Líamos os artigos da propaganda republicana e comparecíamos aos comícios em que se propugnava a abolição ou a mudança de regime. De manhã, depois dos exercícios, havia uma fileira de alunos que iam até o Hospital Nacional, ou ainda mais longe, ao encontro do vendedor de jornais, que aliás nunca faltava e tinha uma legião de assinantes. A 'Federação', órgão do grupo republicano riograndense do sul, redigida por Júlio de Castilhos, passava de mão em mão, era disputada e lida com entusiasmo; o mesmo se dava com os jornais republicanos de São Paulo: Os artigos de Rui Barbosa e Quintino Bocaiúva entusiasmavam os cadetes". (Apud Araripe, 1960, p. 104) O biógrafo Gen. Tristão Alencar Araripe reconhece, em especial, "a influenciação de Benjamin Constant na formação ideológica de Tasso Fragoso" (Araripe, 1960, p. 139).

18 As lições referentes à Guerra da Tríplice Aliança resultaram, com segurança, da complementação empreendida por Olavo Bilac, mesmo porque antes da morte de Macedo os programas do Colégio Pedro II não relacionaram o evento no rol dos conteúdos previstos.

${ }^{19}$ As descrições que detalham estratégias e táticas militares podem ser ilustradas pelo seguinte extrato que expõe como se operou a realização desse plano: “(...) o exercito, composto de 20,000 homens, principiou, em 22 de julho, a executar uma 'marcha de flanco', partindo de Tuyuty, afim de cahir sobre a esquerda do exercito paraguayo. Para chegar a Tuyucué, e d'hai operar sobre Humaytá, as nossas forças tiveram de fazer um rodeio de 10 leguas. $\mathrm{O}$ márquez de Caxias dirigia a marcha, tendo sob as suas ordens a vanguarda, que era commandada por Osório, uma divisão argentina ao mando de Gelly y Obes, e o corpo principal do exercito, commandado pelo general Argollo. Ao mesmo tempo, a esquadra preparava-se para forçar a passagem de Curupaity." (Macedo, 1913, p. 410)

${ }^{20}$ Numa nota de rodapé, por exemplo, Maia afirma ter sido "testemunha ocular" da conferência entre Lopes, Mitre e Flores em Jatahyti-Corá. Flores teria se retirado antes de concluída a conferência, por ter "repellido energicamente algumas phrases de Lopes offensivas á dignidade do Estado Oriental e ao Brazil". Após cinco horas, Mitre e Lopes "trocaram os rebenques” e se separaram (Maia, 1886, p. 376).

${ }^{21}$ O plano de Macedo frustrou-se nas lições que se acrescentaram quando da atualização do manual, em 1905. As "explicações" praticamente foram excluídas. Para exemplificá-las, toma-se o conjunto de termos e expressões referentes à lição XXI, "Guerra Hollandeza": "Regeneração politica de Portugal", "Haya", "Triumvirato", "Conspiração", "Licenciar officiaes", "Intolerância religiosa" e "Insurreição". Aos termos e expressões seguem-se as explicações acerca de seus significados. 
${ }^{22}$ Não preciso encarecer o papel do mestre no meio da organização que reclamo para o ensino público.

Ele é o princípio e a vida da escola.

Sem mestre todo ensino é impossível. O mestre no centro da escola é o mesmo que o motor no centro de uma fábrica ou de um engenho. Como faltando o motor o engenho ou a fábrica fica sem movimento; faltando o mestre, a escola não pode trabalhar. (Oliveira, 2003, p. 203)

${ }^{23}$ No programa de 1856, uma expressiva observação demonstra que a matriz do curso de "Historia Pátria" era, ainda, o de História Moderna, daí preconizar alguns cuidados ao professor da matéria. Por ser muito ilustrativa, segue-se a observação completa:

"N.B. Como em falta de livros especiaes, o programma de historia moderna vai accommodado aos compendios francezes, cumpre que o professor de historia pátria em cada huma de suas prelecções sobre as epocas do Brasil, observe aos discipulos; $1^{\circ}$. quaes erão os Reis portuguezes nessa quadra; $2^{\circ}$. quaes os factos mais importantes de seu reinado." (Apud Vechia e Lorenz, 1998, p. 35)

${ }^{24}$ Nas origens, a "postila" era texto elaborado pelo aluno, decorrente de prévios "comentário, explicação, explanação" do mestre. Poderia ser elaborada, também, a partir de ditado direto deste. Como se observa, no Colégio Pedro II, "postila" já correspondia a um recurso didático elaborado pelo professor. O Novo Aurélio: século XXI traz um esclarecedor verbete: "[Da expr. do lat. Escolástico post illa (verba auctoris), 'após aquelas palavras do autor'.] S. f. 1. V. apostila (5). 2. Comentário, explicação, explanação. 3. Explicação ditada pelo professor e escrita pelo aluno.” (Ferreira, 1999, p. 1617)

${ }^{25}$ Nas matérias de conteúdo universal ou relacionadas às línguas e respectivas literaturas utilizavam-se manuais didáticos portugueses. Também eram recomendados outros manuais europeus, de início na própria língua de origem, em especial o francês. Persistindo o seu uso, com o passar do tempo a tendência foi a de traduzi-los para o português.

${ }^{26}$ O responsável pela atualização da $10^{\mathrm{a}}$. Edição, Olavo Bilac, afirma na "Advertencia" inserida após o prefácio: "Encarregado, pelo editor das Lições de Historia do Brasil do dr. Joaquim Manoel de Macedo, de completar este compendio, tratei, antes do mais, de respeitar o plano adoptado pelo seu autor. Era isso o que me cumpria fazer, para não sacrificar o caracter de um livro, que já nove edições successivas consagraram." Seguem-se o local, Rio de Janeiro, a data, 14 de novembro de 1905, e as iniciais do nome do atualizador.

${ }^{27}$ João Ribeiro foi recomendado como fonte para História do Brasil nos programas do Colégio Pedro II de 1915. A vigência desses programas se estendeu até o ano de 1925. Mesmo não identificando a obra indicada, trata-se, por exclusão, de História do Brasil, cuja relevância é atestada pela sua permanência no tempo. Ainda recentemente foi alvo de uma nova reedição pela Editora Itatiaia, dentro da Coleção Reconquista do Brasil, "revista e completada" por Joaquim Ribeiro (Ribeiro, 2001, 290 p.).

Artigo recebido em: 09/09/2009

Aprovado para publicação em: 22/09/2009 